\title{
Correction to: Stationary and Nonstationary Ion and Water Flux Interactions in Kidney Proximal Tubule: Mathematical Analysis of Isosmotic Transport by a Minimalistic Model
}

Erik Hviid Larsen and Jens Nørkær Sørensen

\section{Correction to:}

Chapter "Stationary and Nonstationary Ion and Water Flux Interactions in Kidney Proximal Tubule: Mathematical Analysis of Isosmotic Transport by a Minimalistic Model" E. H. Larsen and J. N. Sørensen, Rev Physiol Biochem Pharmacol, DOI: 10.1007/112_2019_16

The chapter 'Stationary and Nonstationary Ion and Water Flux Interactions in Kidney Proximal Tubule: Mathematical Analysis of Isosmotic Transport by a Minimalistic Model' has now been made available open access under a CC BY 4.0 license and the copyright holder has been updated to 'The Author(s)'.

Further, in Fig. 7e the left-hand side axis label was published incorrectly as being $\mathrm{p}^{\text {cell }}$ (Atm) instead of the correct label of $\mathrm{p}^{\text {lis }}$ (Atm). This has now been corrected. The updated Fig. 7 is shown below. 

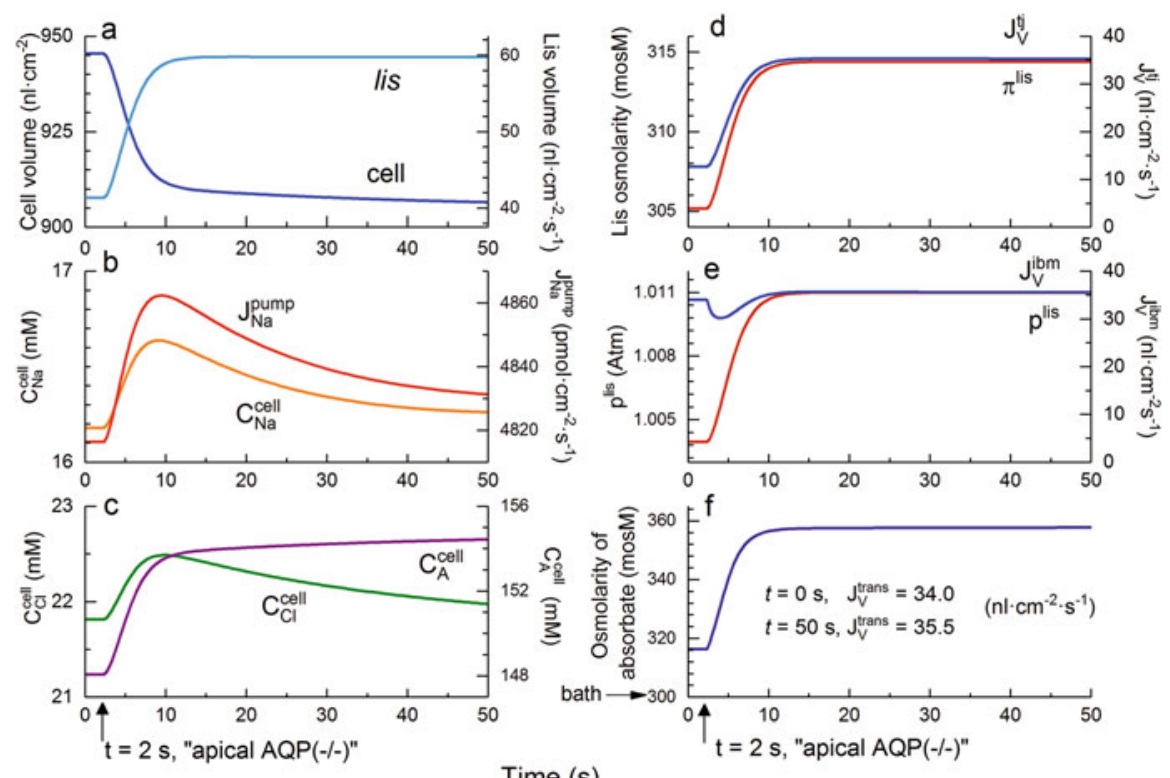

Time (s)

Fig. 7 (a-f) Time course of physiological variables in response to "eliminating" osmotic permeability of apical membrane. At time $=2 \mathrm{~s}$ and governed by $\tau=1 \mathrm{~s}, P_{f}^{a m}$ was reduced exponentially from 4,490 to $0.449 \mu \mathrm{m} \mathrm{s}^{-1}$. (a) this results in a fast shift of water volume from cells to lis. (b) $C_{N a}^{\text {cell }}$ increases transiently, which stimulates $\mathrm{Na}^{+}$pump flux, $J_{N a}^{\text {pump }, l m}$. (c) While the transient increase in $C_{C l}^{c e l l}$ parallels the transient increase in $C_{N a}^{\text {cell }}$, the increase in concentration of nondiffusible anions is closely following the loss of cell volume. (d) The water flux is redirected from being translateral to being paracellular driven by the increased osmolarity of lis governed by the $C_{N a}^{c e l l}$-stimulated increase in $J_{N a}^{\text {pump }, l m}$. (e) Due to inflow of water, the hydrostatic pressure of lis increases, which drives the volume flux across the interspace basement membrane $J_{V}^{i b m}$. (f) The final result is a significant increase in osmolarity of the fluid emerging from lis due to convection-electrodiffusion of solutes across the interspace basement membrane (Eq. 6). Notably, at the new steady state, the transepithelial water flux is about the same as the water flux prior to eliminating $P_{f}^{a m}$ (35.5 versus $34.0 \mathrm{~nL} \mathrm{~cm}^{-2} \mathrm{~s}^{-1}$ ) 